\title{
COMUNICAÇÃO PÚBLICA DIGITAL: REFLEXÕES TEÓRICAS PARA A ANÁLISE DE PORTAIS GOVERNAMENTAIS
}




\title{
COMUNICAÇÃO PÚBLICA DIGITAL: REFLEXÕES TEÓRICAS PARA A ANÁLISE DE PORTAIS GOVERNAMENTAIS
}

\section{Resumo:}

O presente artigo discute os portais governamentais, enquanto estratégias de comunicação pública. Através da discussão teórica sobre as inovações comunicativas da internet, pretende-se pensar o relacionamento entre Estado e cidadãos, por meio dos portais de governo eletrônico. Neste sentido, nossos objetivos são levantar pressupostos teóricos atuais sobre o tema e compreender como a internet pode servir à aproximação entre as esferas política e civil, dada a desconexão entre as duas nas sociedades democráticas contemporâneas.

Palavras chave: Internet; Comunicação pública; Governo eletrônico

\section{COMUNICACIÓN PÚBLICA DIGITAL: REFLEXIONES TEÓRICAS PARA EL} ANÁLISIS DE SÍTIOS WEB GUBERNAMENTALES

Resúmen:

El presente artículo abarca sobre los sitios gubernamentales mientras estrategias de comunicación pública. A través de la discusión teórica sobre las inovaciones comunicativas de la internet, se suele pensar la relación entre Estado y ciudadanos por medio de los sitios web. Siendo así, nuestro objetivo con este trabajo es de apurar presupuestos teóricos actuales sobre el tema y compreender como la internet puede aproximar las esferas política y civil; una vez vista la desconexión entre las dos sociedades democráticas contemporáneas.

Palabras Clave: Internet; Comunicación pública; Gobierno eletrônico

\section{PUBLIC DIGITAL COMMUNICATION: THEORETICAL REFLECTIONS FOR THE ANALYSIS OF GOVERNEMENT PORTALS}

\begin{abstract}
:
This article argues about the government portals, as strategies of public communication. Through theoretical discussion about the communicative innovations of internet, we intend to think the relationship between state and citizens, trough government electronic portals. In this sense, our goals are to raise current theoretical assumptions about the issue and to understand how the Internet can serve to approximation between the political and civil spheres, given the disconnection between the two in contemporary democratic societies.
\end{abstract}

Keywords: Internet; Public communication; E-government 


\section{INTRODUÇÃO}

A Comunicação Pública, sua prática, estratégias e abordagem teórica no país, estão sendo acompanhadas pelo Grupo de Pesquisa Comunicação Organizacional e Institucional/CNPq, desde 2006, através de estudos de graduação e de mestrado. Percebe-se preocupação dos pesquisadores do tema e de profissionais que exercem a Comunicação Pública em delimitar esta comunicação como a que prima pelo interesse público e pela relação dialógica entre Estado e Cidadãos. Em contraponto, percebemos que há necessidade de evoluir na discussão teórica, especialmente diante do contexto midiatizado, permeado pela dinâmica dos usos das tecnologias de informação e comunicação. Deste modo, este estudo nasce do interesse em discutir sobre as inovações que a internet oferece à comunicação pública, através de portais governamentais, para a constituição de um espaço alternativo de comunicação entre Estado, governantes e cidadãos. Nessa perspectiva, a temática contempla a comunicação pública digital, com ênfase à discussão sobre os portais governamentais.

Nosso principal objetivo é levantar pressupostos teóricos atuais sobre o emprego das tecnologias de comunicação e informação (TICs), nos processos comunicativos do Estado, especialmente no relacionamento com os cidadãos. No mesmo sentido, propomos a discussão sobre o conceito de comunicação pública, para delimitar pressupostos necessários ao desenvolvimento de portais de "governo eletrônico", prática mais usual de apropriação das TICs nas esferas municipal, estadual e federal.

O artigo está estruturado em três partes principais. Na primeira seção, a discussão aborda, sinteticamente, os termos democracia e cidadania, para caracterizar que não buscamos questionar modelo de democracia representativa, o conceito de cidadania ou propor formas de propiciar a participação civil nas instâncias políticas decisórias, através da internet. A reflexão caminha no sentido de pensar a comunicação pública na criação de condições para que seja superada a atrofia da função do cidadão, provendo informação e promovendo o diálogo e o debate. Os principais autores utilizados são Cortina (2005) e Gomes (2005a; 2005b; 2011).

$\mathrm{Na}$ segunda seção, abordaremos o conceito de comunicação pública, trazendo à tela algumas questões essenciais que permeiam a construção do conceito. As principais referências serão Brandão (2007), Duarte (2007), Monteiro (2007), Zémor (1995), Matos (1999). A compreensão que temos sobre a comunicação pública, aproxima-se de um conjunto de pressupostos, mais do que um conjunto de práticas, que prima pelo interesse público, e que deve nortear os processos comunicativos do Estado, incluindo-se aí, as estratégias empregadas nos portais governamentais.

Na última parte do artigo, apresentamos o conceito de governo eletrônico, entendido como uma forma aplicada de comunicação pública, em ambiências digitais. A principal referência será Pinho (2008). Também serão apresentados dados do último levantamento sobre inclusão digital, desenvolvido pelo Comitê 
Gestor de Internet no Brasil. Ao final, apresentamos as considerações finais.

\section{O CIDADÃO POLÍTICO: ORIGEM E DIFICULDADES CONCEITUAIS}

A palavra "Democracia" tem origem grega e designa "poder do povo". Cortina (2005) descreve que, desta experiência democrática ateniense, surge, nos sec. V e IV A.C., o ideal de cidadão político, que pertence e participa ativamente de uma comunidade política, nos séculos V e IV A.C. Tinha-se como premissa, que a palavra é a "arma" mais potente para o cidadão assegurar que sua vontade seja feita, mais efetiva do que a força e a imposição, agindo coletivamente através da deliberação, para a legitimação decisória, em última instância, através do voto. Partindo-se desta premissa, a cidadania é exercida através da convivência e do relacionamento com os demais indivíduos, membros de uma coletividade, para decidir o que é melhor, justo ou injusto.

O ideal de cidadão participativo está na essência dos modelos de democracia participativa, aquela em que o povo governa, ainda que mais se aproxime de um mito, mais aplicado às linhas da vasta bibliografia, do que propriamente à vida cotidiana. Algo que fica evidenciado nas limitações entre a teoria do modelo ateniense e o que se via na prática (CORTINA, 2005).

A primeira limitação está em dois tipos de exclusão: somente homens adultos, filhos de pais cidadãos atenienses, podiam votar. Mulheres, crianças e escravos não participavam. A segunda, liberdade e igualdade eram "privilégios" apenas dos cidadãos atenienses, não dos demais seres humanos. A terceira, a liberdade do cidadão ateniense é para a participação em deliberações sobre assuntos públicos, porém a sua vida privada estava exposta às interferências da assembleia. Por fim, a participação direta efetivava-se apenas em comunidades reduzidas, excluindo-se os grandes impérios e os Estados nacionais (CORTINA, 2005).

Outra observação refere-se ao fato que, embora houvesse a possibilidade de participação, os cidadãos não dispendiam muita energia para participar. Em determinados momentos, o exercício da cidadania participativa tornou-se remunerado e, ainda que a época seja anterior ao surgimento dos partidos políticos, já havia organizações voluntárias entre pessoas próximas, parentes e amigos, engajados numa causa própria. Não está entre os objetivos deste estudo fazer uma analogia direta entre os problemas que estão na origem do conceito e os que vivenciam as sociedades democráticas contemporâneas, mas caracterizar que a marginalização de grupos da sociedade das instâncias políticas decisórias, transcende a discussão sobre o modelo democrático. Trazendo a reflexão para o contexto democrático brasileiro, pode-se inferir que a reclusão, o desinteres- 
se e o descaso da esfera civil com a causa pública, são o reflexo da falta de condições para a participação igualitária e de reconhecimento sobre a efetividade das contribuições.

O resultado desta atrofia do papel do cidadão é o que Gomes (2005a) caracteriza como abismo entre as esferas política e civil. Perceptível, de um lado, na descrença e ausência de expectativas da sociedade frente ao pleito e aos governantes e, de outro, na conduta descompromissada dos políticos com os cidadãos, seja no modo de ofertar informações e na restrição ao diálogo, seja na autonomia decisória que se autoconcede e que a sociedade avaliza ao consentir.

Ainda em Gomes (2005a), há, no centro deste quadro, a cultura política dos cidadãos, que carece, nas democracias atuais, de "um elementar sentido de efetividade das práticas civis. Parece ausente a esta mentalidade a sensação de que há uma conexão entre causa e efeito entre a ação do cidadão e o modo como as coisas referentes ao Estado se decidem" (GOMES, 2005a, p.60). A "política" precisaria ter algum sentido para os cidadãos, ocupar lugar na sua escala de valores para que eles se sintam motivados à ação, ao engajamento, à participação.

Frente a este quadro, o ambiente da internet, em seu surgimento, despertou expectativas mais otimistas e, no limite, utópicas, sobre a superação destas dificuldades. Alimentada pelo ideal do cidadão ateniense, a esperança era de que, com a horizontalidade dos fluxos de informação, livres de filtros e de controle, os cidadãos poderiam deliberar livremente sobre a condução dos negócios públicos. Porém, superada esta fase e constatado que a internet, por sí só, não pode contribuir para a democracia, pode-se inferir deste quadro e da explanação de Cortina (2005), que a questão não reside na técnica, na internet como solução para a marginalização da esfera civil das instâncias decisórias políticas, nem no modelo democrático vigente, pois como descreve Gomes (2011), há continuidades entre os modelos de democracia antiga e democracia moderna, na medida em que esta nasce da impossibilidade de "todos" os cidadãos interferirem em "todas" as instâncias políticas decisórias.

E, ainda, a concepção de democracia representativa tem como premissa assegurar a soberania do povo, evitando o enfraquecimento da sua vontade frente à atuação dos representantes eleitos, como, por exemplo, através da realização de plebiscitos e a própria eleição sistêmica. A inobservância à transparência e à prestação de contas, por exemplo, é maléfica para ambos os modelos democráticos.

Portanto, a reflexão aqui proposta não busca um novo modelo democrático, não tem esta pretensão. Pelo contrário, pretende-se apenas pensar a comunicação pública, entendida como aquela entre Estado, governo e sociedade civil, com objetivo de informar e dialogar sobre assuntos de interesse coletivo, para a construção e o exercício da cidadania. Ou ainda, pensar a contribuição da comunicação pública digital para o relacionamento entre Estado e sociedade civil, para atenuar a atrofia da função do cidadão, de vigiar, controlar, sugerir e questionar a condução do Estado. Para tanto, informação, transparência, diálogo e debate público são algumas das premissas da comunicação pública e 
alguns dos aspectos essenciais para criar as condições necessárias à aproximação entre as esferas política e civil, devolvendo à palavra ao povo, não para governar diretamente, mas para garanti-lo sentimento de pertença à coletividade e a sensação de efetividade de suas contribuições democráticas.

\section{COMUNICAÇÃO PÚBLICA: UM CONCEITO EM CONSTRUÇÃO}

Ao abordarmos o conceito de comunicação pública, entendemos ser necessário explicitar a compreensão que temos sobre comunicação, frente às distorções entre os significados dos termos "informação" e "comunicação". Ambas estão inter-relacionadas e são necessárias à democracia, mas a comunicação é mais complexa e envolve a subjetividade dos sujeitos, pois ocorre na relação entre eles. Já a informação é a mensagem e faz parte de um projeto de comunicação (WOLTON, 2010).

Ao situar o aspecto relacional da comunicação, desvia-se o foco das tecnologias e de uma percepção quantitativa sobre a informação, para salientar a necessidade de sintonia entre os sujeitos em relação e as resistências impostas pelos receptores. Dito de outro modo, a reflexão aponta às condições necessárias para que a comunicação ocorra, para que a mensagem seja aceita ou recusada pelos receptores. Num momento em que as tecnologias tornam todas as diferenças visíveis, com a proliferação de informações através da internet, o resgate do significado de comunicação ilumina aspectos essenciais à convivência democrática, como compartilhamento, negociação e convivência (WOLTON, 2010).

Nesse sentido, ao repensar a relação entre informação e comunicação, Wolton (2010) não nega os benefícios da tecnologia para a comunicação social, mas sublinha que as tecnologias "nunca serão suficientes para resolver as aporias existenciais da comunicação humana" (WOLTON, 2010, p.31). Propor "destecnologizar" a comunicação não significa, então, negar a tecnologia, mas situar que a comunicação é humana e não técnica. Assim, para a reflexão sobre a comunicação pública, deve-se ter como pressuposto, que a comunicação ocorre entre os sujeitos, políticos e cidadãos e, independente do suporte empregado, a informação não é a única variável para assegurar que a relação se estabeleça.

Devido à liquidez do termo, aplicável a diferentes abordagens teóricas, a complexidade aparece quando se se propõe a sua aplicabilidade (WEBER, 2007). Esta é uma afirmação recorrente entre pesquisadores da área, no Brasil (BRANDÃO, 2007; DUARTE, 2007; MONTEIRO, 2007).

As pesquisas em comunicação pública iniciaram no país na década de 90 e, desde então, há um esforço entre pesquisadores para chegar a uma definição conceitual. Desde a tradução de La Communication Publique (1995), de 
Pierre Zémor, feita por Elizabeth Brandão, este texto tem sido referência para vários desses estudiosos.

Para ilustrar a complexidade e as dificuldades conceituais, Monteiro (2007) pesquisou o termo "comunicação pública" em sites de busca, na internet, e encontrou mais de dois milhões de resultados, em vários idiomas, com aplicações e finalidades bastante distintas, como em artigos científicos e divulgação de cursos de graduação e de pós-graduação.

Brandão (2007) reforça este discurso, porém destaca que já há em comum, entre os pesquisadores, o entendimento de que "diz respeito a um processo comunicativo que se instaura entre o Estado, o governo e a sociedade com o objetivo de informar para a construção da cidadania" (BRANDÃO, 2007, p.9), sendo este o significado que permeia a construção do conceito nos estudos acadêmicos, no Brasil. No mesmo horizonte discursivo, Duarte (2007) também afirma o compromisso com o cidadão: "é uma expressão que não especifica um conjunto de conhecimentos, áreas, profissões ou estruturas, estando mais próximo de se caracterizar como um etos, uma postura de perceber a comunicação como instrumento de interesse coletivo para fortalecimento da cidadania" (DUARTE, 2007, p.60). Nas instituições públicas, relacionam-se às iniciativas que visam à transparência da administração pública que, por vezes, é ofuscada pelos interesses políticos e partidários.

Quando compreendida como a comunicação realizada entre Estado (ou governo) e cidadãos, a comunicação pública tem sido empregada com o objetivo de aproximar a comunicação do Estado ao conceito de democracia e de afastá-la em definitivo da idéia de persuasão e de manipulação, marketing e propaganda política, herança de outras épocas da história do país, anteriores à instauração da democracia constitucional. Desde a restauração democrática do Brasil, em 1988, há a necessidade de estimular o exercício da cidadania, o que levou o conceito em direção a um ideal democrático, quase utópico, vertente que influencia a concepção de comunicação pública até hoje (BRANDÃO, 2007).

Na publicação do Diário Oficial da União, do dia 07 de junho de 2011, consta instrução normativa que estabelece alguns conceitos relacionados à comunicação do Poder Executivo Federal. "Comunicação Pública” está entre eles, assim definida

(...) a ação de comunicação que se realiza por meio da articulação de diferentes ferramentas capazes de criar, integrar, interagir e fomentar conteúdos de comunicação destinados a garantir o exercício da cidadania, o acesso aos serviços e informações de interesse público, a transparência das políticas públicas e a prestação de contas do Poder Executivo Federal.

Esta definição regulamentada converge com as contribuições dos autores supracitados, na medida em que enfatiza o cidadão, a transparência, conteúdos de interesse público e a prestação de contas. Porém, percebe-se que 
prevalece a ênfase informativa, relacionada ao papel do Estado de prover informações aos cidadãos.

Em relação à necessidade de diálogo e de sensibilidade do Estado às vozes da sociedade civil, noções essenciais à saúde democrática do país, a referência que mais se aproxima na redação do texto da instrução normativa é "interação". Ainda assim, definida como resultado da combinação entre "ferramentas" de comunicação, não há a especificação se ela ocorre entre Estado e cidadãos, entre cidadãos e ferramentas de comunicação ou ainda apenas entre cidadãos.A ênfase na comunicação bilateral aparece no conceito de "comunicação digital", entendida como "a ação de comunicação que consiste na convergência de conteúdo, mídia, tecnologia e dispositivos digitais para acesso, troca e interação de informações, em ambiente virtual, dos órgãos e entidades do Poder Executivo Federal com a sociedade ou com públicos específicos". Chama-nos a atenção, a dissociação de comunicação pública, o que nos leva a crer sobre a importância atribuída à comunicação digital pelo Poder Executivo Federal, na medida em que recebe uma tipificação própria. Porém, devido à centralidade dos processos informativos e interativos para a democracia, entendemos que poderia haver um conceito "híbrido", mais próximo às discussões acadêmicas que contemplam as virtudes da comunicação digital e da comunicação pública, para a potencialização das ações do governo Federal com finalidades cidadãs e democráticas.

Nos conceito de comunicação pública apresentado no Diário Oficial da União, não há um conjunto de práticas que determine o que ela é, assim como também não há nos estudos acadêmicos. A orientação passa mais por preceitos, finalidades, critérios mais subjetivos e menos palpáveis relacionados ao que ela deve visar, oferecer, aos valores que deve privilegiar. Neste sentido, Duarte (2007) salienta alguns aspectos essenciais que devem ser preconizados:

(a)compromisso em privilegiar o interesse público em relação ao interesse individual ou corporativo; (b) centralizar o processo no cidadão; (c) tratar comunicação como um processo mais amplo do que informação; (d) adaptação dos instrumentos às necessidades, possibilidades e interesses dos públicos; (e) assumir a complexidade da comunicação, tratando-a como um todo uno (DUARTE, 2007, p.59).

Dos aspectos citados, não há a preocupação delimitar o emissor, restringindo-a, por exemplo, à comunicação do Estado, do governo e de instituições públicas. Assim, a definição do que é a comunicação pública está menos em quem produz as mensagens e em práticas específicas, e mais na natureza das mensagens, que deve priorizar o interesse coletivo, sem privilegiar indivíduos ou grupos sociais. Portanto, organizações privadas e do terceiro setor podem realizar comunicação pública, como em ações de que visam benefícios ambientais e sociais.

Monteiro (2007) também desenvolve esta reflexão, através da investi- 
gação sobre a singularidade da comunicação pública. Deslocando o foco do emissor para a natureza das mensagens, permite afirmar que a comunicação pública pode ocorrer em qualquer lugar, sem precisar da mediação dos meios de comunicação, mas precisa oferecer condições para o debate, a manifestação e a troca de idéias, como em ouvidorias e audiências públicas. Portanto, a comunicação pública não é determinada pelo emissor, tampouco pelos meios empregados, mas se manifesta pela intenção de promover a discussão, o debate, informar para a construção e exercício da cidadania, podendo ocorrer em peças gráficas, em portais da internet, na televisão e no rádio.

Além do diálogo, a autora inclui entre as finalidades da comunicação pública, a obrigação de informar, de prestar contas, de otimização dos processos comunicativos do serviço público, campanhas de divulgação de interesse coletivo e a necessidade da comunicação agir no sentido de aproximação do cidadão das esferas decisórias políticas.

As contribuições de Duarte (2007) e Monteiro (2007) também convergem ao afirmar que a comunicação pública deve ser orientada pelo interesse no e do cidadão, superando a ideia de prestação de informações. A ênfase no receptor subentende a preocupação em tornar a informação compreensível a todos, permitir e estimular a participação dialógica, para a construção de uma relação perene e de credibilidade entre os interlocutores.

Destas considerações, a vertente teórica sobre comunicação pública aqui empregada, segue uma perspectiva dialógica, enfatizando a importância da relação para que o interesse dos cidadãos seja no próprio conteúdo cognitivo, enquanto resposta aos seus anseios e desejos. Propõe-se pensar na comunicação pública digital enquanto processo e continuidade, em estratégias perenes, sem isentá-la de interesses políticos e dos "tensionamentos off-line", pois não há a desconexão entre virtual e real, no âmbito da sociedade midiatizada (SODRÉ, 2002), na medida em que se intersectam e se confundem. A comunicação pública digital precisaria refletir aquilo que seus fluxos representam, e é exatamente aí, no real, que reside a descrença, o descrédito e a desconfiança de políticos e partidos.

Diante disto, entendemos que, hoje, a utilização da internet na comunicação pública do Estado, pode representar a oportunidade de atualização e de potencialização dos espaços tradicionais de comunicação e de expressão da sociedade, na medida em que possibilita contatos com pessoas espacialmente dispersas, de qualquer local do território nacional, que tenha acesso à internet. Porém, não depende apenas da técnica, nem de um conjunto de iniciativas pré -estabelecidas, que determinam o que é e o que não é comunicação pública, mas de valores, pressupostos que devem nortear todos os processos comunicativos do Estado, além de transformações na cultura política dos cidadãos (GOMES, 2005a), que extrapolam a reflexão do âmbito da comunicação.

\section{COMUNICAÇÃO PÚBLICA E INTERNET: O GOVERNO ELETRÔNICO}

O conceito de "governo eletrônico" ou "e-gov" vem a designar o proces- 
so de implementação das TICs nos setores governamentais. Entre os principais objetivos do uso destas tecnologias está a informatização dos processos comunicacionais com os públicos internos e externos, estes representados pelos cidadãos, fornecedores e outros setores do governo. Para desenvolver esta discussão, adotamos a proposta de "governo eletrônico ampliado", de Pinho (2008). Entre as possibilidades de uso das TICs, delimitamos o interesse nos portais governamentais, iniciativa mais usual entre os governos municipais e federais. A opção pela proposta de Pinho (2008) também se justifica, por entendermos que mais se aproxima da compreensão que temos sobre comunicação pública, podendo assim, caracterizar uma estratégia de comunicação pública digital.

A criação de portais governamentais é uma oportunidade de abertura do governo e Estado, onde "mostram sua identidade, seus propósitos, suas realizações, possibilitam a concentração e disponibilização de serviços e informações, o que facilita a realização de negócios e o acesso à identificação das necessidades dos cidadãos" (PINHO, 2008, p.473). Assim, através dos portais, Estado e governo concentram os processos comunicativos com os diversos públicos com os quais se relacionam.

Na literatura que aborda a temática, encontram-se denominações para caracterizar a relação eletrônica do governo com cada tipo de público. Por exemplo: Government-to-Business (G2B), a informação, produto ou serviço é disponibilizado por um ente governamental e quem irá receber ou consumi -lo será uma empresa; Government-to-Government (G2G), a relação se dá entre dois entes governamentais (JOIA e CAVALCANTE NETO, 2004). Para este estudo, que concentra a atenção na esfera de produção de conteúdos, é relevante um tipo de relação: government-to-citizen ( $\left.\mathrm{G}_{2} \mathrm{C}\right)$.

A denominação government-to-citizen $\left(\mathrm{G}_{2} \mathrm{C}\right)$ vem a designar a oferta de serviços e informações do governo para os cidadãos. Tais iniciativas encontram na internet um ambiente que permite que isto ocorra de forma mais ágil, organizada, segmentada, além de constituir um arquivo amplo e irrestrito de informações, com acesso em tempo integral e com custos reduzidos para manutenção (JOIA e CAVALCANTE NETO, 2004). Para Pinho (2008), a característica de fluxos predominantemente unilaterais (G2C) é restritiva e propõe que ela seja ampliada.

A concepção ampliada de governo eletrônico não desqualifica a anterior, mas pressupõe maior abertura do governo, adotando-se uma postura mais transparente sobre seu posicionamento ideológico e sobre a condução do governo. Neste sentido, a possibilidade de interagir com mais frequência com os cidadãos, ouvindo suas demandas, desejos e opiniões, contribui para atenuar o afastamento entre as esferas civil e política e caracterizam o posicionamento ideológico de um governo eletrônico ampliado, que vai além das práticas políticas tradicionais.

Dentro dessa perspectiva, acrescentam-se, além do objetivo de informar e de disponibilizar serviços, o aumento da transparência e participação da sociedade nas ações governamentais. Pinho (2008) endossa que as TICs têm um 
enorme potencial para que estes objetivos sejam atendidos, porém isto só será possível desde "que haja definição política no sentido da participação popular e da transparência, pois o governo pode deixar de oferecer o que não quer mostrar, para nem mencionar o que quer esconder" (PINHO, 2008, p.475). Por isso, a reflexão sobre as oportunidades democráticas não recai somente sobre os fluxos de informação do ambiente virtual da internet, mas nas ações daqueles que detém o controle da informação.

Desloca-se o foco. A reflexão sai do ambiente virtual da internet, para o ambiente em que a internet se insere. É papel dos governantes, enquanto representantes eleitos e gestores da comunicação do Estado, superar uma série de valores e práticas enraizadas na política brasileira, inclusive as relacionadas ao emprego dos meios de comunicação. Em âmbito mundial, Pinho (2008) observa a sobreposição das nações que dominam as TICs sobre as demais, o que - leva a afirmar que as oportunidades democráticas "devem ser relativizadas ante um contexto das forças de dominação e poder que, aliás, também fazem uso dessas próprias tecnologias para manter seu status de dominação" (2008, p.476). E, complementa, mesmo nos países mais desenvolvidos, os governos eletrônicos ainda não atingiram o estágio ampliado.

A atuação ainda é restrita, principalmente no que respeita à transparência ou accountabillity, entendida como "o engajamento dos governantes com a prestação de contas, e também a responsabilização dos governantes pelos seus atos" (PINHO, 2008, p.478). Para o autor, a transparência é essencial para deslocar a sociedade civil da condição de expectadora na condução do Estado. Destarte, agrega-se, além do Estado e das TICs, um terceiro aspecto essencial para atenuar a desconexão entre governo e cidadão: a capacidade política dos cidadãos, para vigiar, propor, questionar e debater com o governo.

Diante dessas considerações, compreendemos que o ambiente virtual traz inovações significativas para a comunicação entre Estado e cidadãos, mas adotamos cautela quanto aos seus efeitos democráticos. Para complementar e justificar esta posição ponderada, vejamos alguns dados retirados do site do Comitê Gestor da Internet no Brasil. Os dados da Pesquisa Tic Domicílios 2009 demonstraram que a exclusão digital ainda é presente no país e que ainda há lacunas a preencher quanto à ampliação da inclusão digital e ao acesso às tecnologias de informação, nas classes economicamente menos favorecidas. As pessoas de classes A e B ouvidas, respectivamente, $85 \%$ e $72 \%$ utilizaram a internet nos três meses que antecederam a pesquisa. Dos entrevistados pertencentes à classe C, $42 \%$ tiveram acesso à internet no referido período. Já entre as classes E e F, apenas $17 \%$ das pessoas têm acesso à internet. Ainda que este percentual não seja muito expressivo, houve evolução em relação à aferição realizada no ano anterior.

A pesquisa também revela o incremento da aquisição de computadores, saltando de 47\% (em 2008) para 54\% (em 2009), e do acesso à Internet em casa, que cresceu de $42 \%$ para $48 \%$. Ainda, $63 \%$ dos jovens entre 10 e 15 anos de idade 
têm acesso à internet. Entre os entrevistados situados na faixa etária entre $16 \mathrm{e}$ 24 anos, o percentual sobe para $68 \%$. Nas faixas etárias subseqüentes, as taxas decrescem em relação às faixas anteriores, porém também demonstram crescimento em relação à mesma faixa de idade no levantamento do ano anterior.

De uma maneira geral, a importância dos dados apresentados está no avanço, em todas as faixas etárias investigadas, especialmente nas gerações mais jovens, do acesso ao computador e à internet. Nesse sentido e diante das considerações anteriores, cabe a reflexão de Gomes (2005b), que aponta a superação da fase mais entusiasmada dos estudos sobre os impactos sociais e políticos da internet e que seria, então, o momento propício para avaliar os impactos da internet para a democracia. Ainda, grande parte da crítica dirigida à internet, está justamente na exaltação das suas possibilidades positivas, sem bases mais concretas para sustentação dos argumentos. "Em suma, o adversário em geral é menos a internet e mais a retórica sobre a internet e os imaginários ciberentusiasmados que prosperam na academia e no jornalismo" (GOMES, 2005b, p.19).

Por fim, nossa argumentação redunda em afirmar que, como descreve Levy (1999), não se deve pensar a técnica como uma entidade real, pois ela é criada e tem o seu uso definido pelo homem. Compreendemos a internet como um meio alternativo e, se superadas as dificuldades de acesso e de inclusão, de intensificação dos contatos entre Estado e cidadãos. Porém, além de prover o acesso e adequar os conteúdos à capacidade cognitiva dos cidadãos, variável bastante complicada pelas desigualdades culturais, econômicas e educacionais da população, tem que existir audiência e esta não nasce apenas da oferta.

Cremos que a audiência parte do relacionamento e da construção conjunta e sistêmica, através da reaplicação de cada conhecimento obtido nos processos comunicativos, entre Estado e cidadãos, na busca pelo aperfeiçoamento da comunicação pública e o estreitamento dos laços entre os dois polos envolvidos. Quem sabe assim, refletidas essas preocupações, tem-se a transição da percepção da internet, enquanto esfera de visibilidade política, para um ambiente de informação e de comunicação pública.

\section{CONSIDERAÇÕES}

A argumentação desenvolvida nos permite perceber que a comunicação pública digital não ocorre dissociada do ambiente em que é produzida e, por isto, as potencialidades comunicativas da ambiência da internet, não podem operar uma transformação social e política, capaz de superar todas as dificuldades democráticas contemporâneas. Ainda assim, são inegáveis as oportunidades que a internet traz às instituições públicas e ao Estado para intensificar e melhorar a comunicação pública, relativas à possibilidade de fluxos horizontalizados e bilaterais de informação; disponibilização de quantidades maiores de conteúdos; combinação de múltiplos suportes de mídia, através da capacidade multimídia da ambiência digital; superação de limitações espaciais e temporais; 
otimização de serviços públicos; entre outros.

Entendemos que a adequação da comunicação pública ao contexto midiatizado contemporâneo, precisa contornar a lógica de consumo de informações e de prevalência da forma sobre o conteúdo. Mais do que informações, recursos estéticos e imagéticos, a comunicação pública deve ser pautada pela relação entre Estado e cidadão, adequando suas mensagens às demandas destes. Pela perspectiva dialógica empreendida neste estudo, estabelecendo-se um processo de contínuas trocas entre os dois polos, o conteúdo cognitivo tende a ser o próprio objeto de interesse.

Temos ciência das dificuldades que se situam entre a teoria e a prática, frente às disputas do jogo político. Mas acreditamos que a separação entre o que é de interesse político e o que respeita à coletividade tornar-se-ia secundária se o benefício político se originasse da opção por primar pelo interesse público. Assim, temos a compreensão de que privilegiar o interesse público pode ser uma fonte de benefícios mútuos entre Estado, governantes e cidadãos.

Para que a internet não se constitua em mais um espaço concorrencial de visibilidade política, a comunicação pública, através dos portais governamentais, precisaria ser impregnada por valores democráticos e cidadãos. Mas por que deveríamos crer nisto, se os meios de comunicação tradicionais também têm potencialidades excepcionais para a comunicação entre Estado e cidadãos e tiveram seus usos desvirtuados dos fins democráticos? Não sabemos se é esta a questão central, mas entendemos que este é um dos caminhos, sem a intenção de esgotar o assunto, mas de tecer argumentos preliminares para aprofundamento teórico em estudos futuros.

\section{REFERÊNCIAS}

ANDERSON, Chris. A cauda longa. Do mercado de massa para o mercado de nicho. Rio de Janeiro: Elseiver, 2006.

BRANDÃO, Elizabeth Pazito.Conceito de comunicação pública. In: DUARTE, Jorge. Comunicação pública: estado, mercado, sociedade e interesse público. São Paulo: Atlas, 2007. CASTELLS, Manuel. A sociedade em rede. A era da informação: economia, sociedade e cultura. São Paulo: Paz e Terra, 1999.

CORTINA, Adela. Cidadãos do mundo: para uma teoria da cidadania. São Paulo: Loyola, 2005.

DUARTE, Jorge (organizador). Comunicação Pública: Estado, governo, mercado e interesse público. São Paulo: Atlas, 2007.

. Instrumentos de comunicação pública. Comunicação Pública: Estado, Mercado, Sociedade e Interesse Público / Jorge Duarte, organizador. São Paulo: Atlas, 2007. GOMES, Wilson. Internet e participação política em sociedades democráticas, Encontro Latino de Economia Política da Informação, Comunicação e Cultura 2005. Disponível em: <http://www.gepicc.ufba.br/enlepic>. Acessado em: 08/05/2011. 
Fronteiras - estudos midiáticos. Vol. VII Nº 3 - setembro/dezembro 2005.

. Participação política online: questões e hipóteses de trabalho. In: MAIA, Rousiley C. M.; GOMES, Wilson; MARQUES, Francisco Jamil Almeida. Internet e Participação Política no Brasil. Porto Alegre: Sulina, 2011. 19-46.

JOIA, Luiz Antonio. NETO, Aristides Andrade Cavalcante. Fatores críticos de sucesso na construção de processos government-to-government. Revista Organizações e Sociedade, $\mathrm{n}^{\circ}$ 29. Salvador, V.11, $\mathrm{n}^{\circ}$ 29. Jan-abr|2004.

LEVY, Pierre. Cibercultura. São Paulo: Ed. 43, 1999.

MATOS, Heloiza. . Comunicação pública, democracia e cidadania. Líbero, ano 2, n³ 3/4, 1999. MONTEIRO, Graça França. A singularidade da comunicação pública. Comunicação Pública: Estado, Mercado, Sociedade e Interesse Público / Jorge Duarte, organizador. São Paulo: Atlas, 2007.34-46.

PINHO, J. A. G. de. Internet, governo eletrônico, sociedade e democracia no Brasil: algumas questões básicas em debate. Revista VeraCidade, v.7, p.35-49, 2008. PRIMO, Alex. O aspecto relacional das interações na Web 2.0. E-Compós (Brasília), v. 9, p. 1-21, 2007.

SILVA, Sivaldo Pereira da. Graus de participação democrática no uso da internet pelos governos das capitais brasileiras. Revista Opinião Pública, Campinas, Vol.XI, n², p.450-468, $2005 a$.

. Sivaldo Pereira da. Política e ciberespaço: graus de participação democrática no uso da internet pelos governos das capitais brasileiras. 2005b. 197f. Dissertação (Mestrado em Comunicação e Cultura Contemporânea) Universidade Federal da Bahia, Faculdade de Comunicação.

Democracia online: pressupostos teóricos e inovações estruturais na comunicação do Estado contemporâneo. In: CONGRESSO DA ASSOCIAÇÃO BRASILEIRA DE PESQUISADORES EM COMUNICAÇÃO E POLÍTICA, 3, 2009, São Paulo. Anais... São Paulo: Pontifícia Universidade Católica de São Paulo, 2009.

SODRÉ, Muniz. Antropológica do Espelho. Por uma teoria da comunicação linear e em rede. Petrópolis, RJ: Vozes, 2002.

WEBER, Maria Helena. Na comunicação pública, a captura do voto. Logos- Comunicação e Universidade, UERJ, a.14, n.27, 2.sem.2007.

WOLTON, Dominique. Informar não é comunicar. Porto Alegre: Sulina, 2011.ZEMOR, Pierre. La Communication Publique. Paris: PUF, 1995.

Post sobre a Palestra “Comunicação Pública: a Experiência Francesa. 24 de abril de 2009. Brasília, DF, 2009. In: http://carlosscomazzon.wordpress.com/2009/04/29/para-especialistas-comunicacao-publica-prioriza-cidadao/ Acesso em 19 nov, 2010. 


\section{Bruno Kegler}

Doutorando em Comunicação pela Universidade Federal do Rio Grande do Sul. Mestre em Comunicação pela Universidade Federal de Santa Maria - UFSM (2011). Especialista em Marketing e Recursos Humanos pela Faculdade Metodista de Santa Maria (2007). Graduado em Comunicação Social - Habilitação Publicidade e Propaganda (UFSM/2006) e pesquisa na área de Comunicação Institucional e Publicidade Regional.

\section{Maria Ivete Trevisan Fossá}

Possui doutorado em Administração pela Universidade Federal do Rio Grande do Sul (2003), mestrado em Comunicação Social pela Universidade Metodista de São Paulo (1997), especialização em Formação de Professores de Disciplinas Especializa pela Universidade Federal de Santa Maria (1981), graduação em Comunicação Social - Relações Públicas pela Universidade Federal de Santa Maria (1978) e graduação em Administração pela Universidade Federal de Santa Maria (1980. Atualmente é Professor Adjunto da Universidade Federal de Santa Maria. 